\title{
SUBPRIME MORTGAGES AND LENDING BUBBLES
}

\author{
Ali Yavuz Polat ${ }^{1}$ \\ ${ }^{1}$ Department of Economics, Abdullah Gul University, Kayseri, Turkey. \\ Email: aliyavuzpolat@gmail.com
}

\begin{abstract}
We consider a model with two types of households: the poor with no initial endowment and the rich with positive endowment, and two types of assets: properties in a poor area and properties in a rich area. In the model, poor agents need credit to buy an asset, whereas the rich can draw from their endowment. We show that credit-fueled housing bubbles sometimes may improve welfare, making the poorer individuals better off. More precisely, there exist two types of equilibria in both property markets: one is a bubble equilibrium, and the other is an equilibrium where asset prices are stable over time. While the poor always obtain a positive surplus in the bubble equilibrium, this is not necessarily true for the rich. Our results suggest that there may be scope for market interventions aimed at sustaining the value of assets held by credit-constrained agents after the burst of a credit bubble.
\end{abstract}

Keywords: Subprime mortgage; Bubbles; Credit; Equilibria; Household asset.

JEL Classifications: D14; G10; G21.

Article history:

Received : July 7, 2018

Revised : : September 16, 2018

Accepted : October 17, 2018

Available online : October 31, 2018

https://doi.org/10.21098/bemp.v21i2.955 


\section{INTRODUCTION}

The years preceding The Global Financial Crisis (GFC) witnessed unprecedented access to credit for low income individuals with little or no credit history. This was partly facilitated by government-sponsored institutions like Fannie Mae and Freddie Mac, whose main task was to incentivize banks to extend the credit base by buying securitized loans from commercial banks, especially subprime loans. Later, after the GFC, the US Government was criticized for this policy, which was considered one of the fundamental reasons for the credit-fueled housing bubble (especially the subprime bubble). This paper tests whether credit-fueled bubbleswhere the price of an asset is above the fundamental value-sometimes make poor agents (subprime borrowers) better off and improve welfare. The argument relies on the idea that asset price bubbles can improve intergenerational allocation of resources in the presence of financial frictions, such as borrowing constraints. In principle, the bubble may make the poor better off through various channels. One such channel is short-term borrowing. When the house owned by a poor individual gains value, it can be used as collateral to start a business. For example, consider a scenario where the poor with access to good investment opportunities require short-term credit. If house prices are high (overvalued), the poor may be able to collateralize the house and borrow, whereas if their houses are significantly underpriced they may not be able to access credit at all. This argument is similar to Tirole (1985), who argues that even if bubbles crowd out total investment, they still may improve the flow and allocation of funds through relaxing the borrowing constraint for investors with a good investment opportunity, that is, the bubble can lead to a Pareto improvement.

Another channel is mobility. With the possibility of selling their houses at a high price, poor households can enjoy higher socio-economic and geographic mobility. Consider, for instance, a scenario where a homeowner may want to move to a better neighborhood. If his property is overvalued, it can be sold or collateralized to obtain credit to purchase a property in the new neighborhood. However, mobility is instead hindered if the assets owned by the poor are significantly underpriced. A branch of the mobility literature shows that mobility is negatively affected when house prices fall due to negative equity. Being trapped in negative equity due to a significant decrease in house prices is called a "lock-in effect" (Ferreira, Gyourko, and Tracy, 2010).

We consider a model with two types of households: the poor (with no initial endowment) and the rich (with some endowment), and two types of assets: a house in a poor area (a poor asset) and a house in a rich area (a rich asset). In the model, poor agents need credit to buy an asset, whereas the rich can draw from their endowment. In other words, the poor need a 100\% loan-to-value (LTV) mortgage (can be thought of as subprime loans), whereas the rich can provide some down payment. Thus, the equilibrium price for the poor asset is determined by the availability of credit. We show that there exist two types of equilibria for houses in the poor region. One of them is a bubble equilibrium, which exists if credit growth is sufficiently large, that is, a credit-fueled bubble. The other is an equilibrium where the asset price is stable over time but the asset is significantly underpriced. Under the bubble scenario, prices grow fast enough such that the poor who purchased the asset not only can pay back their debt by selling the asset 
when old, but also enjoy a positive surplus. Under the no-bubble scenario, credit growth is small, implying that price growth is not large enough to enable agents to pay back their debt by selling the asset in the future. Thus, in the no-bubble case, the equilibrium price will be zero, that is, the asset is significantly underpriced. The implication of this result is that the bubble scenario makes the poor better off and improves welfare. ${ }^{2}$ For the rich asset market, there are also two types of equilibria: a bubble equilibrium and a no-bubble equilibrium with a price at the fundamental value. In the rich asset market, the price is bounded below by the fundamental value, since the rich can always purchase the asset by paying from their endowment. This, in contrast, is not true for the poor asset, which is always underpriced in the absence of bubbles.

To analyze welfare, we consider an extension where both poor and rich assets depreciate through time. We consider a supplier who can build new houses, whenever the price of the house is higher than the cost. In that case, when the poor asset is underpriced (zero price), the supplier will not find it profitable to build new houses in the poor neighborhood. Thus, over time, the total stock of poor assets will decrease due to depreciation. In contrast, if there is a bubble in the poor market, the supplier will build new houses, keeping the total stock of assets stable. Comparing these two scenarios, the bubble brings a welfare improvement by stabilizing the total stock of poor assets.

One important empirical implication of this model is that bubbles grow faster in the poor market than in the rich market. Moreover, if at any point in time the $100 \%$ LTV policy is abandoned, there will be a mass default among the poor. The intuition of both results is due to poor agents having zero initial wealth and their dependence on credit. ${ }^{3}$ Figures 1 and 2 show the Case-Shiller Home price indexes for both high- and low-tier classes since 1994 for San Francisco and Miami, respectively. ${ }^{4}$ It is evident that bubbles in low-tier home markets are much more pronounced compared to the high-tier. ${ }^{5}$ These figures provide anecdotal evidence to motivate our result that housing bubbles may be more pronounced for assets owned by the poor due to poor home buyers' greater dependence on credit growth. Consequently, downturns affect the low-tier housing market more than the high-tier, that is, price volatility in the poor housing market is higher. In terms of policy, our results suggest that there may be scope for market interventions aimed at sustaining the value of assets held by credit-constrained agents after the burst of a credit bubble.

This paper proceeds as follows. Section II reviews the literature. Section III outlines the model, and Section IV characterizes the equilibria. Section V sets forth extensions of the model. Section VI draws conclusions and implications for policy.

2 However, there is a risk that if the bubble bursts, there may be widespread defaults among the poor. We comment on this issue in the extension section below.

3 As discussed in the conclusion, the zero-wealth assumption is just to make the main point clearer to illustrate. Otherwise, one can consider a model where the poor have some wealth, but significantly a smaller amount than the wealth of the rich. That model will also bring similar results qualitatively as long as the poor and the rich differ from each other significantly enough.

4 See Figures 7, 8, and 9 in the Appendix for Los Angeles, New York, and Tampa.

5 For San Francisco and Miami, the difference between the low and high classes seems to be much more significant. 


\section{RELATED LITERATURE}

Bubbles are studied extensively in the literature and have attracted the attention of economists, academics, and policymakers due to their consequences on the allocation of resources. This section presents an overview of the vast literature on this topic without presenting a detailed discussion. Although there is no consensus among economists on the definition of the term "bubble," one can define a bubble as sustained mispricing of an asset. Not every mispricing can be considered a bubble however. The term bubble refers to a period in which investors believe that price growth will continue, so they hold the asset at the ongoing price-even though it seems to be overvalued-since they believe that the asset can be sold at a higher price in the future. ${ }^{6}$

The literature describes various theoretical explanations for bubbles. ${ }^{7}$ One strand of models is the rational expectations models, where agents have identical information (Martin and Ventura, 2012; Galí, 2014). Considering the possibility of speculation when traders are assumed to have rational expectations, Tirole (1982) derives the conditions under which bubbles can be ruled out. This author shows that at least one of the following four conditions must be violated to sustain a bubble (Barlevy, 2015): (i) the number of potential traders is finite; (ii) all traders are assumed to be rational, which is common knowledge; (iii) traders should hold common prior beliefs about the environment; and (iv) resources are allocated efficiently ex-ante, before the trade. Rational bubbles can exist under restrictive theoretical conditions. Blanchard (1979) shows that it is consistent to have bubbles followed by market crashes under rational expectations. This author also claims that detecting these bubbles seems to be quite difficult. Diba and Grossman (1988) show, due to free disposal, that negative rational bubbles are ruled out. These authors also show that a positive bubble can start only at the first trading day of a stock and a burst rational bubble cannot restart. The present study complements the literature in the sense that it does not focus on the conditions under which a rational bubble exists, but on its welfare implications.

Another strand of literature considers asymmetric information bubbles (or heterogeneous belief models) where agents have different information, but based on a common prior distribution (Harrison and Kreps, 1978; Allen, Morris, and Postlewaite, 1993; Scheinkman and Xiong, 2003; Conlon, 2004; Brunnermeier, 2008; Conlon, 2015). In these models, prices reflect information but, contrary to the symmetric information case, the existence of a bubble may not be common knowledge. ${ }^{8}$ Other literature considers the interaction between well-informed sophisticated investors and behavioral investors, who have psychological biases (De Long et al., 1990; Shleifer and Vishny, 1997; Abreu and Brunnermeier, 2002, 2003). The seminal Shleifer and Vishny (1997) shows that there are limits to arbitrage. Although sophisticated investors understand the overpricing, they may

This type of explanation for the bubbles is termed the "greater-fool theory of bubbles" (Barlevy (2015)).

See Brunnermeier (2008) and Brunnermeier and Oehmke (2013) for an overview.

8 As Brunnermeier (2008) mentions, it can be the case that all agents are aware of the over-valuation of an asset but not everybody knows that all other investors also know of this fact. "This lack of higher-order mutual knowledge" allows for the possibility of the existence of finite bubbles. See also Allen, Morris, and Postlewaite (1993). 
not be able to trade against the bubble. This "limits to arbitrage" argument implies that bubbles can exist, since arbitrageurs cannot drive prices to the fundamental.

The present study is more related to the class of "credit bubble" models, such as Allen and Gale (2000). These authors present a model built on a risk shifting argument. Investors, having limited liability, borrow from banks and bid up asset prices. When the value of their investment turns out to be low, they simply default and walk away. Barlevy (2014) develop a credit-driven bubble model to investigate the possible empirical patterns that can be used as indicators of bubbles. This author suggests that rapid price appreciation, together with high turnover rates and speculative trading, are more likely to take place when assets are overvalued. The present study complements the aforementioned literature focusing on the policy and welfare implications of housing bubbles, rather than the destructive consequences of bubbles or explanations of why bubbles form. Our results may explain why the value of assets owned by the poor may depend more on credit growth. More importantly, we offer a channel through which bubbles may improve the welfare of the poor.

\section{THE MODEL}

We consider an OLG model where each generation lives for two periods. Agents are heterogeneous in their initial endowment. There are two types of agents: the rich with an initial endowment $A>0$, and the poor with no initial endowment. In the economy, there are also two types of assets ${ }^{9}$ whose consumption generate positive utility. More precisely, agent $i \in\{R, P\}(R=$ Rich, $P=$ Poor $)$ derives utility $u_{i}\left(a_{j}\right)$ from the consumption of asset $a_{j} \in\left\{a_{R^{\prime}} a_{P}\right\}$ when young. There is a continuous mass $m$ of poor agents and $n$ of rich agents. Type $a_{R}$ asset represents a residential property in a rich area, whereas $a_{p}$ represents a residential property in a poor area. Consider a segregated city where the rich live in one neighborhood and the poor in the other. We assume that the rich have no intrinsic utility from consumption of a property in the poor area. This is just for simplification and, as long as the rich value the poor asset less than the poor do, our results follow. Formally, we have the following assumption.

Assumption [A1] $u_{R}\left(a_{R}\right)>u_{P}\left(a_{R}\right)>u_{P}\left(a_{P}\right)>u_{R}\left(a_{P}\right)=0$

[A1] basically states that rich agents value the rich asset more than poor agents and rich agents assign no value for the poor asset. ${ }^{10}$ In contrast, poor agents derive some utility from the poor asset, albeit lower than the utility the rich derive from the rich asset.

The assets are fixed in supply. There is a continuum $S^{P}$ of poor assets and $S^{R}$ of rich assets. In any period $t$, the old generation retires and those who hold an asset can sell it to a member of the young generation at some price $p_{t}^{j}, j=R, P$.

A durable consumption good like a residential property.

10 The assumption, $u_{R}\left(a_{P}\right)=0$, is just for simplification. It does not affect our results qualitatively as long as the above utility ranking holds. 
Each agent, either poor or rich, can purchase no more than one house, either as consumers or investors. Moreover, the agents who cannot buy a house obtain zero utility.

\section{Assumption [A2] $m>S^{P}>n>S^{R}$}

[A2] helps us to identify equilibrium prices. Specifically, there are more poor (rich) agents than the supply of poor (rich) assets such that agents compete to buy the assets. The assumption that the supply of poor assets is larger than the mass of rich agents ensures that rich agents will not drive prices in the poor asset market, even if they may be interested in buying a poor asset for speculative reasons. This is discussed in the characterization of the equilibrium in Section IV below.

To simplify the illustration, assume all agents have a discount factor $\frac{1}{r}<1$ per period. ${ }^{11}$

\section{CHARACTERIZATION OF EQUILIBRIA}

We define the fundamental value of asset $a_{j^{\prime}} j \in\{R, P\}$ as:

$$
F^{j} \equiv \frac{u_{i}\left(a_{j}\right)}{r-1}
$$

As will become clear, in equilibrium, the value of asset $a_{\text {in }}$ is entirely determined by the demand of type $j$ individuals. We thus simplify the notation by setting $u_{P}\left(a_{P}\right) \equiv u_{P}$ and $u_{R}\left(a_{R}\right) \equiv u_{R}$.

Consider an equilibrium where banks offer contracts with no initial down payment (100\% LTV ratio), type $i$ young agents borrow $B_{t}^{j}$ from the bank to buy type $j$ asset from the old agents, and the banks demand repayment $r B_{t}{ }^{j}, r \geq 1$. Type $i=R, P$ agent will buy a property when the following holds:

$$
\frac{u_{i}\left(a_{j}\right)+p_{t+1}^{j}}{r} \geq p_{t}^{j}
$$

Consider the following environment:

- Banks are competitive, but assume that for each borrower there is an upper bound for the credit available $\bar{B}_{t}$. This constraint is relaxed at a rate $r_{2}>1$, i.e., $\bar{B}_{t+1}=r_{2} \bar{B}_{t}$. This borrowing constraint may reflect the total amount of

11 Assume that banks borrow from depositors whose discount rate is $\beta$ and there are enough depositors so that the funding cost of banks will be determined by the depositor's discount factor. Considering that the banking sector is competitive, banks will charge $r=\frac{1}{\beta}$. This will imply that the opportunity cost of borrowers in the economy is $\frac{1}{r}$. 
credit available in the economy ${ }^{12}$ and will be crucial for the determination of equilibrium. Whenever the borrower is expected to default, we also assume that banks do not lend, so that $\bar{B}_{t}=0$. This implies that if a bank expects that $p_{t+1}^{j}<r B_{t}^{j}$, such that the anticipated price in the next period is not enough to cover the repayment, then $\bar{B}_{t}=0$.

- In each period $t$, since there are more young than old who own an asset, ${ }^{13}$ the young compete to buy the asset.

Given this environment, consider first the poor asset $a_{P}$. The poor have no initial wealth, so they pay a price such that $p_{t}^{P}=B_{t}^{P}$. Then (2) becomes

$$
\frac{u_{P}\left(a_{P}\right)+B_{t+1}^{P}}{r} \geq B_{t}^{P} .
$$

Also, the young poor cannot pay an amount greater than the maximum borrowing:

$$
p_{t}^{P} \leq \bar{B}_{t}
$$

Lemma 1 For the poor asset market, if there exists a borrowing equilibrium with $B_{t}>0$, then price grows at rate $r$ or higher to avoid default, i.e., $p_{t+1}^{P} \geq r p_{t}^{P}$. This implies that agents obtain a positive surplus, i.e., (2) does not bind.

Proof. In the model, there are two constraints for a young poor agent: the borrowing constraint $p_{t}^{P} \leq \bar{B}_{t}(4)$ and the willingness-to-buy constraint $\left(W T B_{P}\right)$ (2). Due to competition among the young, at any period at least one of these two constraints should bind (otherwise, if both are slack, one can outbid others by paying $p_{t}^{P}+\epsilon<\bar{B}_{t}$ where (2) still holds.). The agents do not default in an equilibrium since they cannot access credit if they are not expected to pay back their debt, i.e., $\bar{B}_{t}=0$ if banks expect that $p_{t+1}^{j}<r B_{t}^{j}$. Thus, no-default requires $p_{t+1}^{P} \geq r B_{t}=r p_{t}$. This implies that agents can borrow only if the price of the poor asset grows at rate $r$ or higher. In turn, this implies that agents obtain a positive surplus since $W T B_{P}$ does not bind. To see this point, note that a binding $W T B_{P}$ would imply that agents cannot pay back their debt:

12 We think that this assumption is related to the credit-fueled bubble that resulted in the global financial crisis. In that sense, due to either government policies (as was the case in the US) or simply due to the banks extending their lending base, there will be some credit growth captured by the parameter $r_{2}$. We place no restriction on the parameter so that any scenario where credit is squeezed can also be captured with parameter $0<r_{2}<1$. However, in the equilibrium characterization, we discuss the cases for $r_{2}>1$ since our focus is shedding light on credit-fueled bubbles.

13 One can also think of the basic assumption of the classical OLG model, where population grows each period at a fixed rate. However, this assumption will be redundant in our model, since, in every period, only some young will get the asset and in the next period, when they become old, the new generation will keep competing for the asset considering that the mass of assets is always less than the young population in each period. Thus, we simply assume that the population is fixed each period. 


$$
\frac{u_{P}\left(a_{P}\right)+p_{t+1}^{P}}{r}=p_{t}^{P} \Rightarrow p_{t+1}^{P}=r p_{t}^{P}-u_{P}\left(a_{P}\right)<r p_{t}^{P}
$$

(5) then implies that in any equilibrium with positive borrowing, $W T B_{P}$ does not bind.

Lemma 2 Suppose [A1] and [A2] hold. Then, in the poor asset market:

i. If $r_{2} \geq r$, there exists an equilibrium with prices $p_{t}^{P}=\bar{B}_{t}$ and $p_{t+1}^{P}=\bar{B}_{t+1}=r_{2} \bar{B}_{t}$ in any consecutive periods. Poor agents who hold an asset obtain a positive surplus, (2) holds with strict inequality, and there are no defaults in equilibrium. ii. If $r_{2}<r$, there is a unique equilibrium with price $p_{t}^{P}=0$ in every period.

Comparing equilibria (i) and (ii), the poor are better off under (i).

Proof. Lemma 1 shows that in equilibrium, (4) must bind due to competition among the young (since $W T B_{P}$ is slack). Thus, in case (i), the young must borrow up to the maximum in equilibrium. Then, equilibrium prices are $p_{t}^{P}=\bar{B}_{t}$ and $p_{t+1}^{P}=\bar{B}_{t+1}=r_{2} \bar{B}_{t}$. Since $r_{2} \geq r$, we have $p_{t+1}^{P}=r_{2} \bar{B}_{t} \geq r \bar{B}_{t}$, implying that agents can pay back their debt and there are no defaults in equilibrium.

A slack in (2) implies that the young who hold an asset obtain a positive surplus:

$$
\frac{u_{P}}{r}+\frac{p_{t+1}^{P}}{r}-p_{t}^{P}=\frac{u_{P}}{r}+\frac{\left(r_{2}-r\right) \bar{B}_{t}}{r}>0
$$

Note that there may also exist no bubble equilibria with prices $p_{t}^{P}=0, \forall t$, if agents expect $p_{t+1}^{P}=B_{t+1}<r B_{t}=r p_{t}^{P}$ at any point in time. The proof is similar to the one provided below.

We now check whether the rich have an incentive to buy the poor asset when $r_{2} \geq r$. Even though they derive no utility, if $r_{2}<r$, the rich may also buy the poor asset to speculate on price growth. But Assumption [A2] indicates that they cannot drive prices, since the mass of the poor asset is bigger than the mass of rich agents. Thus, the marginal buyer is poor and the equilibrium is as established above.

For case (ii), again, as proved above, if there exists a borrowing equilibrium $B_{t}^{P}>0$, it has to be $B_{t}^{P}=\bar{B}_{t}=p_{t}^{P}$. However, considering that $r_{2}<r, p_{t+1}^{P}=r_{2} \bar{B}_{t}<r \bar{B}_{t}$ this implies that the old cannot pay back their debt and default. But, then expecting a default, banks will never give credit, i.e., $\bar{B}_{t}=0$. Thus, the only equilibrium involves $p_{t}^{P}=0, \forall t$.

Now suppose the rich buy the poor asset. Again since $S^{P}>n$, the marginal buyer is a poor agent and thus the previous argument applies. ${ }^{14}$

Comparing the two cases (i) and (ii), in (i) the surplus from purchasing an asset is bigger than that of case (ii). The reason for this is that, when there is a bubble, agents enjoy an excess surplus, on top of the utility they get from consumption, considering that price growth is bigger than the repayment to the bank. Formally,

14 Note that, when $r_{2}<r$, the rich do not have speculative incentives to buy the poor asset, since $u_{R}$ $\left(a_{p}\right)=0$, whereas the poor derive a positive utility even though the price is zero. Thus, even without the assumption $S^{P}>n$, the marginal buyer is a poor agent. 
the surplus under case (i) is $\frac{u_{P}}{r}+\frac{\left(r_{2}-r\right) \bar{B}_{t}}{r}$, where the gain from the price growth is positive $\frac{\left(r_{2}-r\right) \bar{B}_{t}}{r}>0$ for $r_{2}>r$. Whereas the surplus under case (ii) is $\frac{u_{P}}{r}$ since $p_{t}^{P}=p_{t+1}^{P}=0$. Then, comparing the surpluses we get:

$$
\frac{u_{P}}{r}+\frac{\left(r_{2}-r\right) \bar{B}_{t}}{r}>\frac{u_{P}}{r}
$$

Note that here not all young agents obtain an asset. Thus it should be the case that there will be some credit rationing.

Figure 3. Poor asset market equilibrium for $r_{2} \geq r$ where $p_{t}=B_{t}$ and $p_{t+1}=B_{t+1}$ The figure illustrates constraints for the poor when $r_{2} \geq r$.

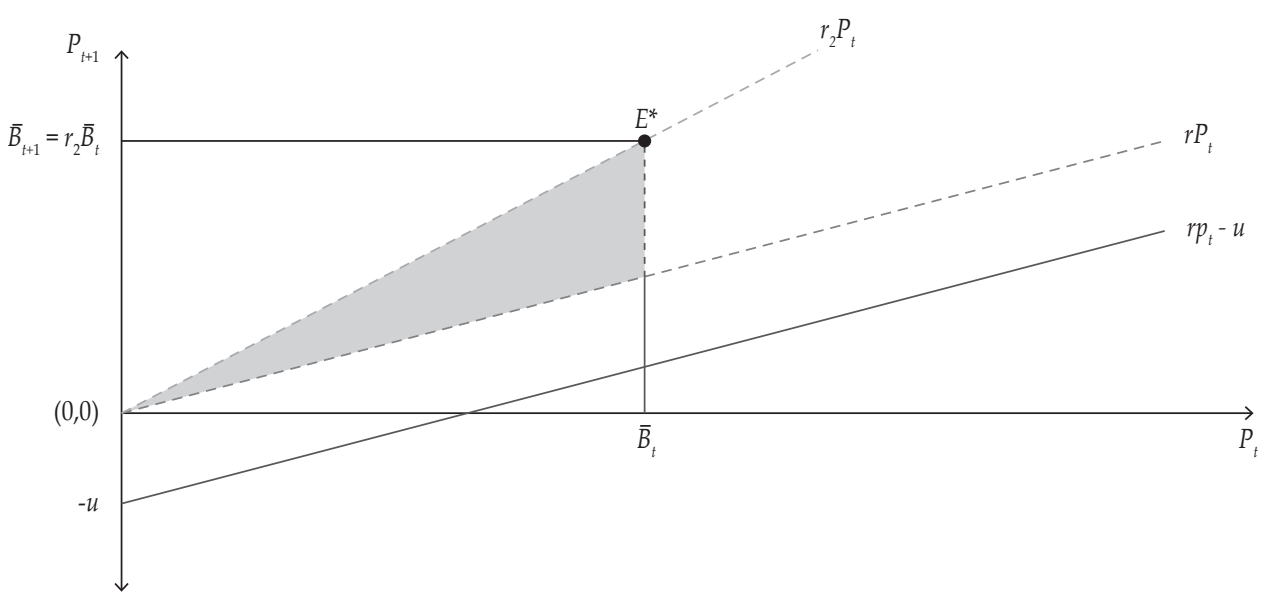

Figures 3 and 4 provide a graphical illustration of the arguments. Figure 3 represents the constraints for the poor when $r_{2} \geq r$. The red lines represent the two main constraints: $W T B_{P}(2)$ and the borrowing constraint (4). Rearranging (2), we get $p_{t+1} \geq r p_{t}-u_{P}{ }^{15}$ The area above this red line represents the willingness-tobuy constraint for the poor $\left(W T B_{P}\right)$. The area on the left-side of $\bar{B}_{t}$ represents the borrowing (resource) constraint. Note that, as proved in Lemma 1, in equilibrium $W T B_{P}(2)$ does not bind considering the no-default condition. Thus, the equilibrium must lie in the area above the blue dotted line $r p_{t}$, which represents the no-default condition. Due to competition among the young, an equilibrium has to be on the dashed-yellow/red line, i.e., the borrowing constraint binds, $p_{t}^{P}=\bar{B}_{t}$ (since WTB $B_{P}$ is slack). But this means that, for the next period, the borrowing constraint also binds $p_{t+1}^{P}=\bar{B}_{t+1}$. Thus, the equilibrium is at point $E^{*}$.

15 Note that for the poor, the price is equal to the borrowing $p_{t}=B_{t}$ and $p_{t+1}=B_{t+1}$. Thus, (2) can also be represented in the graph by $B_{t+1} \geq r B_{t}-u$. 
Note that the $(0,0)$ point in Figure 3 can be also sustained as a no-bubble equilibrium, as long as agents expect the next generation not to borrow (i.e., if agents expect no positive price in the next period) and the price will stay at zero.

\section{Figure 4. Poor asset market equilibrium for $r_{2}<r$}

The figure shows poor asset market equilibrium when $r_{2}<r$.

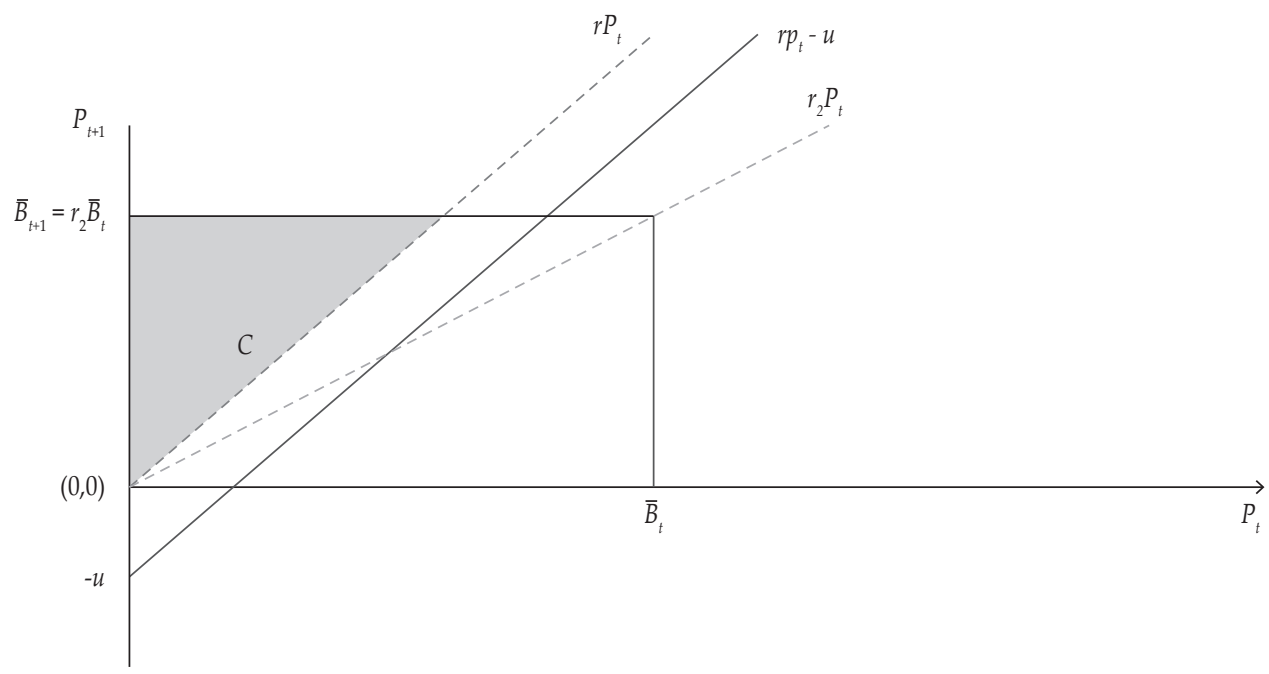

Figure 4 shows the case where $r_{2}<r$. The no-default region is shown by the shaded grey area, and the red lines, the binding constraints (2) and (4), are in the default region. Thus, the equilibrium is at $p_{t}=p_{t+1}=0$. To see that this is indeed the unique equilibrium, consider a point $C$ on the shaded region. But $C$ is off the $W T B_{P^{\prime}}$ i.e., $p_{t+1}>r p_{t}-u$, so that borrowers obtain a positive surplus. In turn, competition among the borrowers implies that the borrowing constraint must be binding. Otherwise, borrowers would have chosen to borrow more to secure the asset. However, any $p_{t}=\bar{B}_{t}>0$ is outside the shaded region, so that default would have occurred. But then, expecting a default, banks will supply no credit. As a result, $\bar{B}_{t}=0$ and the only equilibrium involves $p_{t}=p_{t+1}=0, \forall t$.

As stated above in Lemma 2, there are two main cases in the poor asset market:

i. For $r_{2} \geq \underline{r}$, the young bid the price up to the borrowing limit $p_{t}^{P}=\bar{B}_{t}$ and $p_{t+1}^{P} \stackrel{2}{=} \bar{B}_{t+1}=r_{2} \bar{B}_{t}$, thus implying that price grows at rate $r_{2}$ every period. Under this equilibrium, young poor individuals can pay back their debt, since price growth is fast enough. Thus, there is a bubble equilibrium and for individuals who bought a house ((2)) holds with strict inequality. The price fetched by the asset in the second period of an agent's life is used to repay the principal plus the interest of the loan borrowed $r \bar{B}_{t}$. Banks break even and there are no defaults. Under this parametric case, rich agents may also have an incentive to buy the poor asset-even though they derive no intrinsic utility from it-since price growth is large enough for them to speculate on the bubble. As discussed in the above proof, rich agents' demand does not drive 
prices, since the mass of rich agents is smaller than the mass of poor assets available in the economy. As a result, the marginal buyer is a poor agent.

ii. For $r_{2}<r$, the borrowing constraint is relaxed at a rate smaller than the cost of borrowing $r$, thus implying that even if the poor agent buys the asset by borrowing up to the maximum, price growth is still not large enough to cover the repayment in the next period; i.e., the price fetched by the asset in the second period of life $r_{2} \bar{B}_{t}$ is lower than the repayment, $r \bar{B}_{t}$. This implies that if an agent borrows and purchases a house, the agent will default when old. Thus, the poor asset is not traded at a positive price and there will be an equilibrium where the asset price is below the fundamental, namely $p_{t}^{P}=0$, in every period. In this scenario, no rich agent will have an incentive to buy the asset.

The above discussion implies that there are two types of equilibria for the poor housing market depending on the credit available in the economy. If there is strong credit growth in the economy (case $i$.), there will be a bubble equilibrium where agents who buy a house obtain positive surplus $\left(W T B_{p}(2)\right.$ holds with strict inequality). If there is not enough credit growth in the economy (case ii.), then, in equilibrium, the poor asset is significantly underpriced (the equilibrium price is below the fundamental).

Now, consider the rich asset, $a_{R}$ :

Different from the poor, rich agents have an endowment $A$, which can be used to buy a house.

The rich again have two constraints: the willingness-to-buy constraint $\left(W T B_{R}\right)$

$$
\frac{u_{R}\left(a_{R}\right)+p_{t+1}^{R}}{r} \geq p_{t}^{R}
$$

and the resource constraint

$$
p_{t}^{R} \leq \bar{B}_{t}+A
$$

The rich can pay a down payment $D_{t}$ and borrow $B_{t}$ to buy the house, so that the price of the rich asset is $p_{t}^{R}=B_{t}+D_{t}$. Below, we focus on the case where the down payment is the same in each period, $D_{t}=D_{t+1}=D,{ }^{16}$ so that the price is:

$$
p_{t}^{R}=B_{t}+D
$$

Thus, the willingness-to-buy constraint $\left(W T B_{R}\right)(7)$ can be written as:

16 Note that there can be other equilibria where $D_{t} \neq D$ and it grows each period. We restrict attention to a case where, under a bubble, the rich compete for the asset and, after some point, due to an increase in price, they have to pay their entire endowment. Thus, even though at the initial periods $D_{t}<D$, after some period, the young rich need to pay $D$ to ensure buying the asset. 


$$
\frac{u_{R}\left(a_{R}\right)+B_{t+1}+D}{r} \geq B_{t}+D
$$

and when the maximum is borrowed $\bar{B}_{t+1}=r_{2} \bar{B}_{t}$ we obtain ${ }^{17}$

$$
D \leq \frac{u_{R}}{r-1}+\bar{B}_{t} \frac{r_{2}-r}{r-1}=F^{R}+\bar{B}_{t} \frac{r_{2}-r}{r-1}
$$

First, we need to check whether there can be an equilibrium where rich agents do not borrow, $B_{t}=0$, and simply pay from their initial endowment so that there is no bubble, $p_{t}^{R}=p_{t+1}=D$.

Lemma 3 If $A \geq F^{R}=\frac{u_{R}}{r-1}$, then there exists an equilibrium without borrowing, $p_{t}^{R^{*}}=p_{t+1}^{R^{*}}=F^{R}$ and $B_{t}^{*}=0$. If $A<F^{R}$; thus, in equilibrium, it must be $B_{t}^{*}>0$ (whenever $\bar{B}_{t}>0$ ).

Proof. In any equilibrium, at least one of the constraints (7) or (8) must bind due to the competition among the young (as buyers). Now, consider an equilibrium where the young do not borrow and pay down payment $D$ so that in each period the price equals the down payment, $p_{t}^{R^{*}}=p_{t+1}^{R^{*}}=D$. However, this means that the resource constraint (8) is slack (since agents do not borrow). Thus, (7) must bind, which implies:

$$
\frac{u_{R}\left(a_{R}\right)+D}{r}=D \Rightarrow D=\frac{u_{R}\left(a_{R}\right)}{r-1}=F^{R}
$$

The second part of the lemma follows from the fact that if $A<F^{R}$, then $W T B_{R}$ does not bind, so the resource constraint must bind.

Lemma (3) basically states that, if the endowment $A$ is big enough, there exists an equilibrium where the rich asset is traded at the fundamental value without any bubble (and the price is stable). If the initial endowment is small, then, similar to the poor market, the young borrow to buy the asset, i.e., $B_{t}^{*}>0$ provided that $\bar{B}_{t}>0 .{ }^{18}$

Now consider an equilibrium with a positive amount of borrowing. The rich have resources $A$, which can be used to buy the asset. They already paid $D \leq A$ as a downpayment when they were young. Then, when they are old, the no-default condition is $(A-D)+p_{t+1}^{R} \geq r B_{t}$. Since $p_{t+1}^{R}=B_{t+1}+D$, rearranging the nodefault condition we get:

$$
B_{t+1} \geq r B_{t}-A
$$

Rearranging [WTB_Rich] $\left(W T B_{R}\right)$ we get:

17 Note that we denote $u_{R}=u_{R}\left(a_{R}\right)$ for the rest of the paper.

18 Note that still there may be a no-bubble equilibrium even if $A<F^{R}$. This is proved in Lemma (4). 


$$
B_{t+1} \geq r B_{t}+D(r-1)-u_{R}
$$

Below, Figures 5 and 6 show these two constraints (12) and (13) for the rich when $r_{2} \geq r$ and $r_{2}<r$, respectively. In both graphs, the dotted blue lines represent the no-default conditions and the grey-shaded area presents the pairs $\left(B_{t^{\prime}} B_{t+1}\right)$ where no default occurs. The red and red dotted lines represent the $W T B_{R}$ for $D>F^{R}$ and $D=F^{R}$, respectively. Note that $(13)\left(W T B_{R}\right)$ partially lies within the shaded area for the case $D \geq F^{R}$ (red line).

\section{Figure 5. Constraints for the rich when $r_{2} \geq r$}

The figure illustrates constraints for the rich when $r_{2} \geq r$.

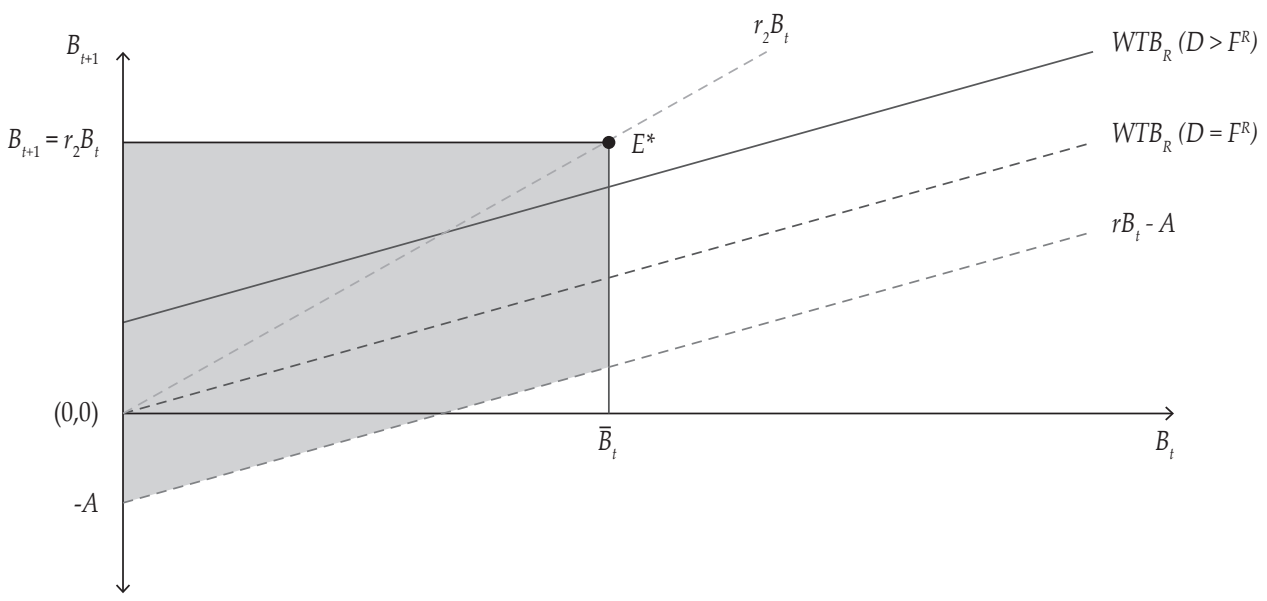

In Figure 5, the maximum borrowing (point $E^{*}$ ) is an equilibrium, though not unique, where the resource constraint binds and the agents obtain a positive surplus. Note that there can be other equilibria (discussed below), such as a point on the $W T B_{R}$ where $D=F^{R}$ and $B_{t+1}=r B_{t}$ so that agents obtain zero surplus (since $W T B_{R}$ binds).

When wealth is smaller than a specific value $\underline{A}=\frac{u}{r}<F^{R}$, then the downpayment has to be small as well, since $D \leq A$, so that the red line $W T B_{R}$ will lie below the default line (the blue dotted line). This case is similar to the poor asset market, where agents are wealth constrained. Thus, to have a meaningful difference between the poor and the rich, we assume that $A$ is large enough. Lemma 6 in the Appendix considers the case where this assumption does not hold. ${ }^{19}$

19 Basically, as shown in the Appendix, if the initial wealth of the rich is smaller than this cut-off $\underline{A}$, as is similar to the poor market, the rich asset will be traded below fundamental, albeit at a positive price. 
Assumption [A3] $A>\underline{A}$ where $\underline{A}=\frac{u_{R}}{r}<F^{R}$.

Figure 6. Constraints for the rich when $r_{2}<r$

The figure illustrates constraints for the poor when $r_{2}<r$.

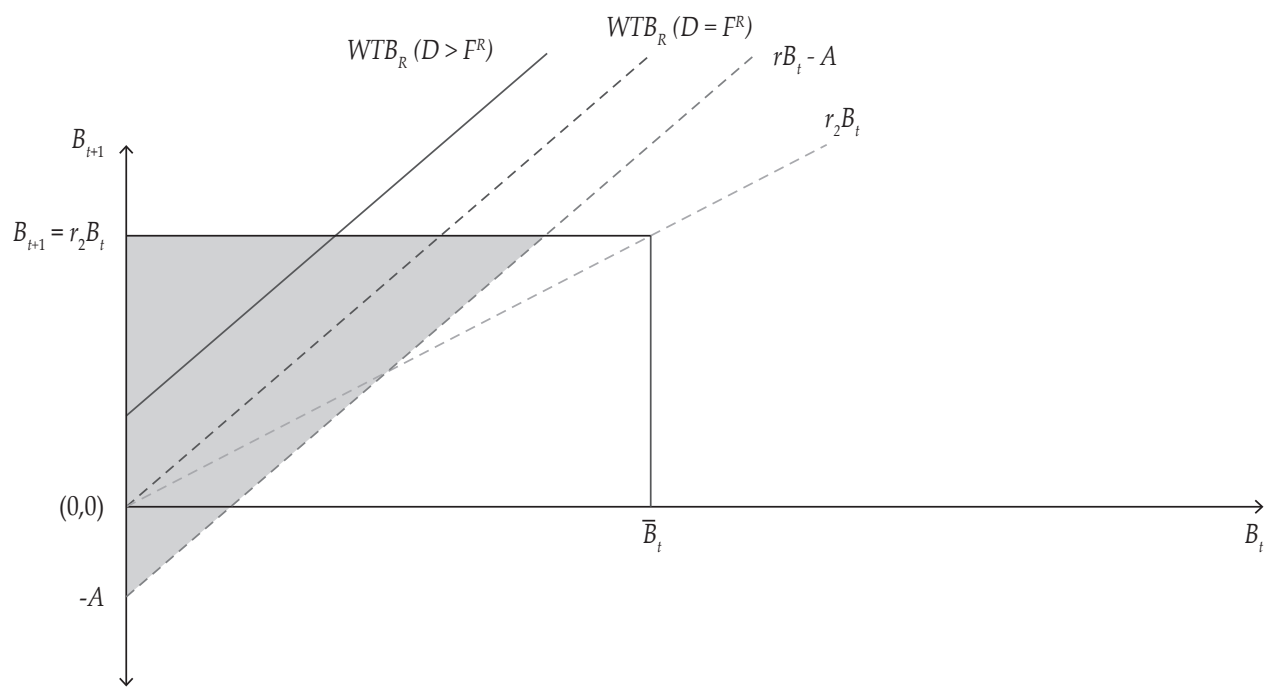

Figure 6 represents the constraints that the rich face when the credit growth rate is smaller than the borrowing rate, i.e., $r_{2}<r$. Considering a candidate bubble equilibrium, there are two possible cases, one where $W T B_{R}$ binds and the other where the no-default (blue dotted line) binds (when [A3] is violated). However, the borrowing level in both these cases (where the equilibrium is on these lines and moving up along the lines) cannot be sustainable, since the credit growth rate $r_{2}$ is smaller than the slope of these lines $r$. Thus, there can exist only steady state equilibria (with no bubble) where $B_{t}=B_{t+1}=B^{*}$ and $D_{t}=D_{t+1}=D^{*}$.

Note that there may be other equilibria where $B_{t}$ and/or $D_{t}$ grow at rates that are not constant. But we restrict attention to balanced growth paths.

Let $\bar{B}_{0}$ be the initial borrowing limit in period 0 .

\section{Lemma 4}

Suppose [A1], [A2], and [A3] hold. Then, in the rich asset market,

i. For the case $r_{2} \geq r$;

a) if $A<F^{R}=\frac{u_{R}}{r-1}$ or

b) if $A \geq F^{R}, r_{2}>r$ and $\overline{B_{0}}$ is sufficiently large,

then there exist balanced bubble equilibria such that the maximum amount is borrowed $B_{t}=\bar{B}_{t}, \forall t$, and rich agents who hold an asset obtain a positive surplus $\left(W T B_{R}(13)\right.$ is slack). The price is $p_{t}^{R^{*}}=\bar{B}_{t}+A$, implying that the resource constraint (8) binds.

c) if $A \geq F^{R}$, there also exist bubble equilibria where the rich agents obtain no surplus in all periods, i.e., $W T B_{R}(13)$ binds.

d) also in all cases, there exist equilibria with no bubble where $p_{t}^{R^{*}}=F^{R}=\frac{u_{R}}{r-1^{\prime}}$ $\forall t$. 
ii. If $r_{2}<r$, there is no balanced growth path involving a bubble; i.e., there exists a continuum of equilibria without a bubble (a steady state) where the asset is traded at the fundamental price $p_{t}^{R^{*}}=F^{R}, \forall t$ such that:

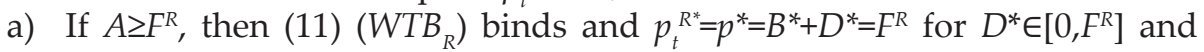
$B^{*} \in\left[0, F^{R}\right]$

b) If $\underline{A}<A<F^{R}$, then $(11)\left(W T B_{R}\right)$ binds and $p_{t}^{R^{*}}=p^{*}=B^{*}+D^{*}=F^{R}$ for $D^{*} \in\left[F^{R}-\frac{A}{r-1}, A\right]$ and $B^{*} \in\left[F^{R}-A, \frac{A}{r-1}\right]$ where $\underline{A}=\frac{u}{r}$.

Proof. We can rewrite the constraints for the rich. $B_{t} \leq \overline{B_{t}} \cdot D_{t} \leq A$.

$$
W T B_{R}: \quad \frac{u_{R}+B_{t+1}+D_{t+1}}{r} \geq B_{t}+D_{t}
$$

If $W T B_{R}$ holds with inequality, then competition implies $B_{t}=\overline{B_{t}}$ and $D_{t}=A$ so that $p_{t}^{R}=\bar{B}_{t}^{R}+A$, i.e., the resource constraint binds.

Then we can rewrite $W T B_{R}$ as follows: $\frac{u_{R}+r_{2} \overline{B_{t}}+A}{r}>\overline{B_{t}}+A \Rightarrow$

$$
u_{R}>\overline{B_{t}}\left(r-r_{2}\right)+A(r-1)
$$

However, we know that $\bar{B}_{t+1}=r_{2} \bar{B}_{t}$. Taking the limit for $t \rightarrow \infty$ shows that (14) can hold for all $t$ only if $r_{2} \geq r$. If also $A<F^{R}=\frac{u_{R}}{r-1}$, then the resource constraint always binds in every bubble equilibrium (and the rich who hold an asset experience positive surplus).

Consider then the case where $A \geq \frac{u_{R}}{r-1}$. We need to look at the initial conditions. If $r_{2}>r$ and $\overline{B_{0}}$ is large enough such that $W T B_{R}$ is slack (i.e., (14) holds at time zero), then we are back to the case above.

If $\overline{B_{0}}$ is small or $r_{2}=r$ so that

$$
u_{R}<\overline{B_{0}}\left(r-r_{2}\right)+A(r-1)
$$

then either $B_{0}<\overline{B_{0}}$ or $D_{0}<A$, or both.

Whenever $A \geq \frac{u_{R}}{r-1}$, bubble equilibria where $W T B_{R}$ binds are also possible. We now construct a bubble equilibrium where $W T B_{R}$ binds.

Suppose that $D_{t}=D$ is constant and $B_{t}$ grows as follows

$$
B_{t+1}=r B_{t}+(r-1) D-u_{R}
$$

then the rich make zero surplus in all periods. Consider a special case where $D=\frac{u_{R}}{r-1}$. Then $B_{t}$ grows at a rate $r<r_{2}$ in every period so that the borrowing constraint (and the resource constraint as well) never binds. 
Note however that there may be other equilibria where $B_{t}$ and/or $D_{t}$ grow at rates that are not constant and satisfy (15). But we restrict attention to balanced growth paths.

\section{For the case (ii), when $r_{2}<r$ :} Note that due to the resource constraint, ${ }^{20}$ the price ratio $\frac{p_{t+1}^{R}}{p_{t}^{R}}$ is bounded above
by $r_{2}$ in the limit for $\rightarrow \infty$. Since $r_{2}<r$,

$$
\lim _{t \rightarrow \infty} \frac{p_{t+1}^{R}}{p_{t}^{R}} \leq r_{2}<r
$$

$W T B_{R}(7)$ implies $\frac{p_{t+1}^{R}}{p_{t}^{R}} \geq r-\frac{u_{r}}{p_{t}^{R}}$ so that even though we have binding $W T B_{R^{\prime}}$

$$
\lim _{t \rightarrow \infty} \frac{p_{t+1}^{R}}{p_{t}^{R}} \geq r>r_{2}
$$

Since we obtain a contradiction, this means that for $r_{2}<r$, there cannot exist a balanced bubble equilibrium.

Thus, consider an equilibrium where the price is constant, $p_{t}^{R}=p^{R *}$. Then, from $W T B_{R^{\prime}}$ it must be that $p^{R^{*}} \leq \frac{u_{R}}{r-1}$. However, due to competition, $p^{R^{*}}<\frac{u_{R}}{r-1}$ cannot be an equilibrium, since otherwise a young agent can pay $p^{R^{*}}+\epsilon$ and obtain the asset for sure. Thus, the equilibrium must be such that $W T B_{R}$ binds (agents obtain no surplus). The price is thus equal to the fundamental value in all periods.

$$
p^{R^{*}}=\frac{u_{R}}{r-1}=F^{R}
$$

The only difference between (ii)(a) and (ii)(b) is the maximum borrowing considering the default cut-off. Formally, at steady state, no default becomes $B^{*} \geq r B^{*}-A$

$$
B^{*} \leq \frac{A}{r-1}
$$

Note that agents have a continuum of choices between borrowing and down payment. This is due to rich agents having two choice variables and the cost of borrowing being the same as the opportunity cost of consumption in the model. In that sense, agents are indifferent between borrowing less and consuming less today

20 Recall that the resource constraint is $p_{t} \leq \bar{B}_{t}+A$ and $p_{t+1} \leq \bar{B}_{t+1}+A=r_{2} \bar{B}_{t}+A$. 
but repaying a lower amount tomorrow vs. borrowing more and consuming more today and repaying a higher amount. Since we are interested in the equilibrium price, this continuum of choices does not affect our argument. ${ }^{21}$

Considering the different possible cases for $r_{2}$, the intuition of Lemma (4) is as follows. Whenever the credit growth rate is larger than the cost of borrowing, there exists a bubble equilibrium where prices grow steadily and agents who hold an asset enjoy a positive surplus. This is due to the fact that the price fetched in the second period of life (when agents are old) is higher than the repayment to the bank.

Whenever the credit growth rate is smaller than the borrowing rate, $r_{2}<r$, borrowing is not sustainable. Since price growth would be smaller than the borrowing rate, ${ }^{22}$ a bubble could not be sustained, since agents would not be able to pay back their debt. Thus, the only equilibrium is a steady state where the rich asset is traded at the fundamental price.

Also note that when the initial credit limit is small and the endowment $A$ is large, there exist bubble equilibria where the rich experience zero surplus.

Lemma 5 As a special case, when $r_{2}=r$, in the rich asset market any borrowing level $0 \leq B_{t} \leq \bar{B}_{t}$ with prices $p_{t}^{R^{*}}=B_{t}+D^{*}$ and $p_{t+1}^{R}{ }^{*}=B_{t+1}+D^{*}$ is an equilibrium where $B_{t+1}=r B_{t}$ and

- $D^{*}=F^{R}$ for $A \geq F^{R}$ and $W T B_{R}$ binds, i.e., the young who hold an asset get no excess surplus

- $\quad D^{*}=A$ for $A<F^{R}$ and $W T B_{R}$ is slack, i.e., the young who hold an asset get excess surplus.

Proof. The poof is similar to case (i) in Lemma 4; the only difference is that $W T B_{R}$ binds for $A \geq F^{R}$.

Proposition 1 Suppose [A1], [A2], and [A3] hold. An equilibrium of this economy consists of price pairs $\left(p_{t}^{j}, p_{t+1}^{j}\right)$ and borrowing levels $B_{t}^{j^{*}}$ for both asset markets $j \in\{R, P\}$ and a downpayment $D^{*}$ for the rich such that,

i. if credit growth is fast, i.e., $r_{2} \geq r$ :

a) in the poor asset market, there exists an equilibrium where agents borrow up to the maximum $p_{t}^{P}=\bar{B}_{t}$ and $p_{t+1}^{P}=\bar{B}_{t+1}=r_{2} \bar{B}_{t}$. Poor agents who hold an asset obtain a positive surplus

b) in the poor asset market, there also exits a steady state with price $p_{t}^{P}=0$ in all periods

21 To understand this point clearly and formally. Consider an equilibrium for case (ii)(a). For the given equilibrium price $p_{t}^{R}=B_{t}+\widehat{D}=F^{R}$ consider two strategies where a young pays $0 \leq \widehat{D}<F^{R}$ at time $t$ and borrows , $B_{t}=F^{R}-\widehat{D}$ vs. a young pays $D=F^{R}$ from the endowment and borrows nothing $B_{t}=0$ so that still pays same price $p_{t}^{R}=F^{R}$. Both of these strategies are equivalent in terms of the utility generated. Since (8) does not bind and willingness-to-buy constraint (7) binds. When $\widehat{D}$ is paid, (7) can be written as $\widehat{D}=\frac{u}{r}+\frac{p_{t+1}-r \bar{B}_{t}}{r} \Rightarrow \widehat{D}+\bar{B}_{t}=\frac{u}{r}+\frac{p_{t+1}}{r}$ whereas when $A$ is paid and $\bar{B}_{t}-(A-\widehat{D})$ is borrowed (7) can be written as $A=\frac{r}{r}+\frac{p_{t+1}-r\left(\bar{B}_{t}-(A-\widehat{D})\right.}{r} \Rightarrow \widehat{D}+\bar{B}_{t}=\frac{u}{r}+\frac{p_{t+1}}{r}$. Thus as long as the resource constraint, (8) does not bind, there exist a continuum of equilibria, $p_{t+1}^{R^{*}}=\bar{B}_{t+1}+\widehat{D}$ where $D \in[\widehat{D}, A]$.

22 Actually, in the rich asset market, the price growth rate should be smaller than the growth rate of credit. 
c) in the rich asset market, if $A<F^{R}=\frac{u_{R}}{r-1}$ or if $A \geq F^{R}, r_{2}>r$ and $\overline{B_{0}}$ is sufficiently large, then there exist balanced bubble equilibria such that the maximum amount is borrowed $B_{t}=\bar{B}_{t}, \forall t$, and rich agents who hold an asset obtain a positive surplus $\left(W T B_{R}(13)\right.$ is slack). The price is $p_{t}^{R^{*}}=\bar{B}_{t}+A$, implying that the resource constraint (8) binds. If $A \geq F^{R}$, then there also exist bubble equilibria where the rich agents obtain no surplus in all periods, i.e., $W T B_{R}(13)$ binds

d) in the rich asset market, there also exists a steady state with price $p_{t}^{R^{*}}=p_{t+1}^{R}{ }^{*}=F^{R}, \forall t$.

ii. if credit growth is smaller than the borrowing rate $r_{2}<r$, then

a) in the poor asset market there exists a unique steady state with price $p_{t}^{P^{*}}=0, \forall t$.

b) in the rich asset market, there exists a steady state (no bubble) where the asset is traded at the fundamental: i.e., $p_{t}^{R^{*}}=p_{t+1}^{R}{ }^{*}=F^{R}, \forall t$ and (11) $\left(W T B_{R}\right)$ binds.

Proof. See proof of Lemmas 2 and 4 above.

When $r_{2}>r$, in the poor asset market, the only alternative to a bubble equilibrium is an equilibrium where the asset is severely underpriced, i.e., $p_{t}^{P}=0$ in all periods. In contrast, in the rich asset market, there exist equilibria where the price is equal to the fundamental. If the young rich expect no price growth, they will pay $p_{t}=F^{R}$. Thus, expectations are crucial in the equilibrium selection.

An interesting observation following from Proposition 1 is that, while the poor always obtain positive surplus in a bubble equilibrium (even though in the steady state), this is not generally true for the rich.

Note also that when credit growth is fast, rich agents also have an incentive to purchase the poor asset to speculate on price growth (even if they derive no intrinsic utility from the poor asset). However, considering [A2], the rich cannot drive the prices in the poor asset market. As for the rich asset market, since the rich can rely on their endowment and value the rich asset more than the poor, they can always price out poor agents since the poor cannot provide a down payment. ${ }^{23}$

Comparing the two types of equilibria (I).(a) and (I).(b), the poor are better off when there is a bubble in the poor asset market.

Proposition 2 For a given credit growth rate $r_{2}>r$, in any bubble equilibrium such that the resource constraint binds, the bubble grows faster in the poor market compared to the rich market.

Proof. Compare the two bubbles in the poor and rich asset markets. For the poor asset, $p_{t}^{P}=\bar{B}_{t}$ and $p_{t+1}^{P}=\bar{B}_{t+1}=r_{2} \bar{B}_{t}$. This implies that the bubble grows at the rate $r_{2}$. For the rich market, $p_{t}^{R}=\bar{B}_{t}+D$ and $p_{t+1}^{R}=\bar{B}_{t+1}+D=r_{2} \bar{B}_{t}+D$. However, this means the growth rate of the bubble is less than $r_{2}$ in the rich market, since $D>0$.

23 Note that this depends on the nature of the contract for the rich. If the contract requires a down payment, then the poor can never buy a rich house. If the contract requires no down payment, then we need to consider a scenario where the price of the poor asset grows faster than that of the rich asset. For example, if the price of the rich asset grows at $r_{2}$ (for the case $r_{2}>r$ ) and the price of the rich asset grows at rate $r$, at some point the poor asset will become more expensive. Thus, we need to assume that the price of the poor asset at any period is bounded by the price of the rich asset. 
The intuition of this result is simple. Since the rich can pay from their endowment, when there is a bubble in the rich market the price grows slower compared to the poor market. This result matches the empirical observations given in Figures 1 and 2.

Several assumptions of the model must be discussed. First, the zero-wealth assumption for the poor simply allows us to present the main idea of this paper in a starker manner. A model where the poor also have some initial wealth, albeit significantly smaller than the wealth of the rich, would generate similar results.

Second, when $r_{2}>r$, i.e., the credit growth rate is larger than the cost of borrowing, there exist ever growing bubbles in both markets. Considering the limited resources, these bubbles cannot be sustained forever, since at some point the bubble will become so big that all the credit of the economy will be allocated to the bubble.

\section{EXTENSIONS}

\section{A. Depreciation}

To illustrate some possible consequences of underpricing, consider an environment where the stock of houses depreciates over time at rate $\lambda \in(0,1)$. More precisely, if no new houses are built in period $\mathrm{t}, S_{t+1}^{j}=\lambda S_{t}^{j}$. Suppose also that there is a producer of houses who can replenish the stock provided that the market price is above the marginal cost. We assume that the producer is a price taker (i.e., can only sell at market price) and has a constant marginal cost $c^{j}$ of producing a type $\mathrm{j}$ house, $j \in\{P, R\}$. Assume

\section{Assumption [A4]. $0<c^{P}<c^{R} \leq F^{R}$}

For simplicity, we restrict attention to the case where the total supply of houses cannot exceed an upper bound $\vec{S}$. For instance, this might be the case if there are building restrictions that limit the amount of land available for building. Similar to the previous sections, we assume

$$
m>\bar{S}^{P}>n>\bar{S}^{R}
$$

Clearly enough, whatever the price at time $t$, an old agent selling his property will receive only $\lambda p_{t}^{j}$. We compare two types of equilibrium: a bubble where the borrowing limit is binding and an equilibrium with no bubble. In general, the surplus generated by the transactions in market $j \in\{P, R\}$ at time $t+1$ is:

$$
W_{t+1}=\underbrace{S_{t+1}^{j}\left[u_{j}+\lambda p_{t+1}^{j}-r p_{t}^{j}\right]}_{\text {Surplus of asset holders }}+\underbrace{\Delta\left[p_{t+1}^{j}-c^{j}\right]}_{\text {Producer Surplus }} .
$$


where $\Delta \geq 0$ denotes production at time $t+1$. (Note that the total surplus (17) does not include the banks' surplus, since credit is modeled in a reduced form. This is however consistent with the competitive case where banks make zero profits).

We restrict our attention to the poor asset market and consider a bubble equilibrium where the producer supplies $(1-\lambda) \bar{S}_{t}{ }_{P}$ in every period, so that $S_{t}^{P}=\bar{S}_{t}$ for all $t$. Assume also that $\lambda$ is not too small, so that $\lambda r_{2}>r$. This implies that price growth allows old agents to repay their debt with the proceeds of the house sale. Then, (17) becomes

$$
W_{t}=\bar{S}^{P}\left[u_{P}+\left(\lambda r_{2}-r\right) \bar{B}_{t}\right]+(1-\lambda) \bar{S}^{P}\left[r_{2} \bar{B}_{t}-c^{P}\right]
$$

At the other extreme, consider now an equilibrium with no bubble (so that $p_{t}^{P}=0, \forall t$ and no new houses enter the market). In this case, (17) becomes

$$
W_{t}=\lambda S_{t}^{P} u_{P}
$$

Clearly enough, (18) is always larger than (19). Moreover, in the second case $\lim _{t \rightarrow \infty} W_{t}=0$, so that the total surplus would converge to zero in the long run. It is also clear that, while a bubble equilibrium may also generate a higher surplus in the rich market, so long as $c^{R} \leq F^{R}$, the supply of rich assets will never go to zero in the long run (so that $\lim _{t \rightarrow \infty} W_{t}>0$ ). This is because the price of the rich asset is bounded below by the fundamental $\mathrm{F}^{\mathrm{R}} .^{24}$

Proposition 3 Suppose Assumption [A4] holds. Then, comparing an equilibrium without a bubble $\left(r_{2}<r\right)$ to an equilibrium with a bubble $\left(\lambda r_{2}>r\right)$, welfare is higher under the bubble scenario.

\section{B. Change in LTV Policy}

Now, consider a scenario where the banks no longer supply $100 \%$ LTV loans. This would mean that the poor cannot access credit, given that they have no endowment. When this change is announced, there is widespread default among the poor, since the young generation cannot receive any credit, implying that the old can find no buyers. Thus, the old at the time of the announcement are unable to pay back their debt. It is possible to enrich the model by endogenizing lending to generate endogenous credit freezes.

24 Note that part of our welfare result is due to the fact that the interest rate $r$ is fixed and does not respond to changed conditions. 


\section{POLICY IMPLICATIONS AND CONCLUSION}

Credit-fueled bubbles, where the price is above the fundamental, may sometimes make poor agents better off compared to a scenario without a bubble, where the poor asset would be significantly underpriced. For example, consider a scenario where the poor with access to good investment opportunities need to take a short-term loan. If house prices are high (overvalued), the poor may be able to collateralize the house and borrow, whereas if their houses are significantly underpriced, they may not be able to access credit at all. This argument is similar to Tirole (1985), who argues that even if bubbles crowd out total investment, they can still improve the flow and allocation of funds through relaxing the borrowing constraint for investors with a good investment opportunity, that is, the bubble can lead to a Pareto improvement.

In terms of policy, our results suggest that there may be scope for market interventions aimed at sustaining the value of the assets held by credit-constrained agents after the burst of a credit bubble.

\section{REFERENCES}

Abreu, D., and Brunnermeier,M.K. (2002). Synchronization risk and delayed arbitrage. Journal of Financial Economics, 66, 341-360.

Abreu, D., and Brunnermeier,M.K. (2003). Bubbles and crashes. Econometrica, 71, 173-204.

Allen, F., and Gale, D. (2000). Bubbles and crises. The Economic Journal, 110, 236255.

Allen, F., Morris, S., and Postlewaite, A. (1993). Finite bubbles with short sale constraints and asymmetric information. Journal of Economic Theory, 61, 206229.

Barlevy, G. (2014). A leverage-based model of speculative bubbles. Journal of Economic Theory, 153, 459-505.

Barlevy, G. (2015) Bubbles and fools. Economic Perspectives, 39, 54-77.

Blanchard., and Jean, O. (1979). Speculative bubbles, crashes and rational expectations. Economics Letters, 3, 387-389.

Brunnermeier., and Markus, K. (2008). Bubbles. New Palgrave Dictionary of Economics, 8. 1.

Brunnermeier., Markus, K., and Oehmke, M. (2013). Bubbles, financial crises, and systemic risk. Handbook of the Economics of Finance, chapter 18. w18398 (Elsevier).

Conlon., and John, R. (2004). Simple finite horizon bubbles robust to higher order knowledge. Econometrica, 72, 927-936.

Conlon., and John, R. (2015). Should central banks burst bubbles? Some microeconomic issues. The Economic Journal, 125, 141-161.

De Long., Bradford,J., Shleifer,A., Summers,L.H., and Waldmann,R.J. (1990). Noise trader risk in financial markets. The Economic Journal, 98, 703-738.

Diba, B.T., and Grossman, H.I. (1988). The theory of rational bubbles in stock prices. The Economic Journal, 98, 746-754.

Ferreira, F., Gyourko,J., and Tracy,J. (2010). Housing busts and household mobility. Journal of Urban Economics, 68, 34-45. 
Galí, J. (2014). Monetary policy and rational asset price bubbles. The American Economic Review, 104, 721-752.

Harrison, J.M., and Kreps,D.M. (1978). Speculative investor behavior in a stock market with heterogeneous expectations. The Quarterly Journal of Economics, 92, 323-336.

Martin, A., and Ventura,J. (2012). Economic growth with bubbles. The American Economic Review, 102, 3033-3058.

Scheinkman, J.A., and Xiong, W. (2003). Overconfidence and speculative bubbles. Journal of Political Economy, 111, 1183-1220.

Shleifer, A., and Vishny,R.W. (1997). The limits of arbitrage. The Journal of Finance, $52,35-55$.

Tirole, J. (1982). On the possibility of speculation under rational expectations. Econometrica: Journal of the Econometric Society, 1163-1181.

Tirole, J. (1985). Asset bubbles and overlapping generations. Econometrica: Journal of the Econometric Society, 1071-1100. 


\section{APPENDIX}

\section{Figure 1. Case-Shiller Home Price Index (High vs Low Tier) for San Francisco, California}

The figure shows the trend in the Case-Shiller home price index (high vs low tier) for California (1994 to 2016).

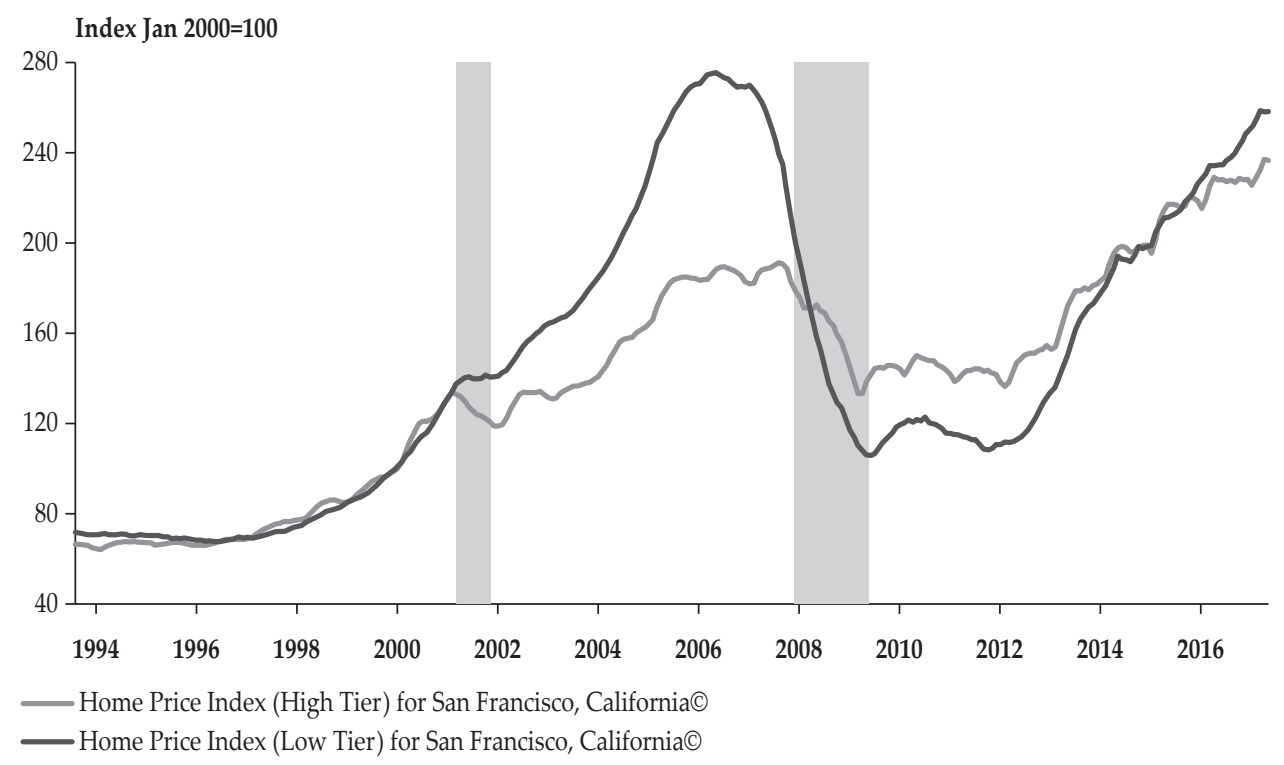

Source: S\&P Dow Jones Indices LLC

Fred.stlouisfed.org 
Figure 2. Case-Shiller Home Price Index (High vs Low Tier) for Miami, Florida

The figure shows the trend in the Case-Shiller home price index (high vs low tier) for Miami, Florida (1994 to 2016).

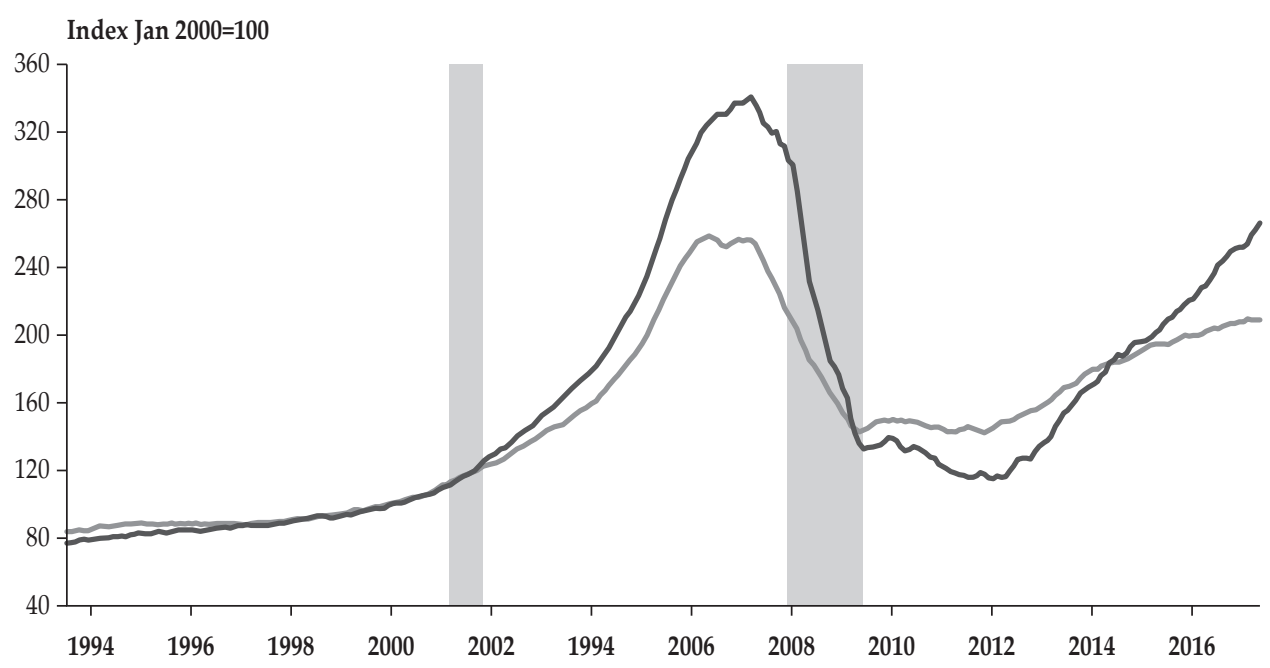

— Home Price Index (High Tier) for Miami, California@

— Home Price Index (Low Tier) for Miami, California@

Source: S\&P Dow Jones Indices LLC

Fred.stlouisfed.org

\section{Figure 7. Case-Shiller Home Price Index (High vs Low Tier) for Los Angeles, California}

The figure shows the trend in the Case-Shiller home price index (high vs low tier) for Los Angeles, California (1994 to 2016).

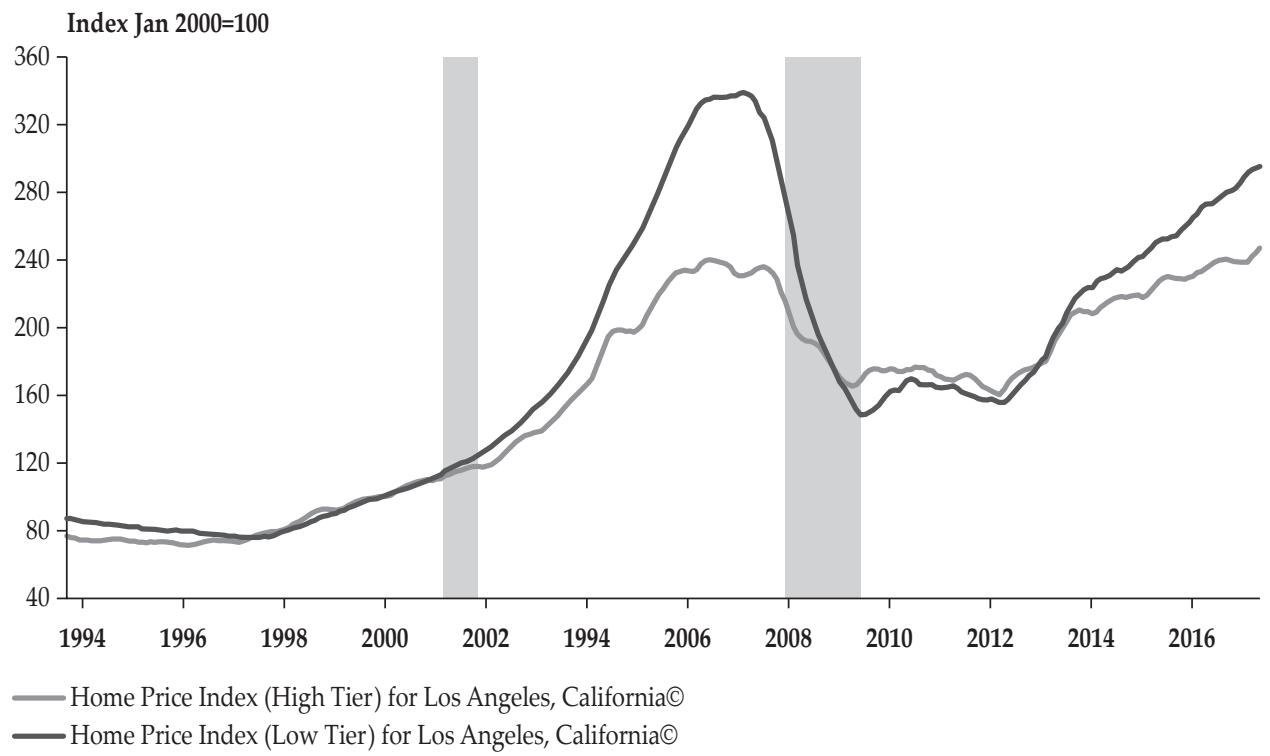

Source: S\&P Dow Jones Indices LLC

Fred.stlouisfed.org 
Figure 8. Case-Shiller Home Price Index (High vs Low Tier) for New York

The figure shows the trend in the Case-Shiller home price index (high vs low tier) for New York (1994 to 2016).

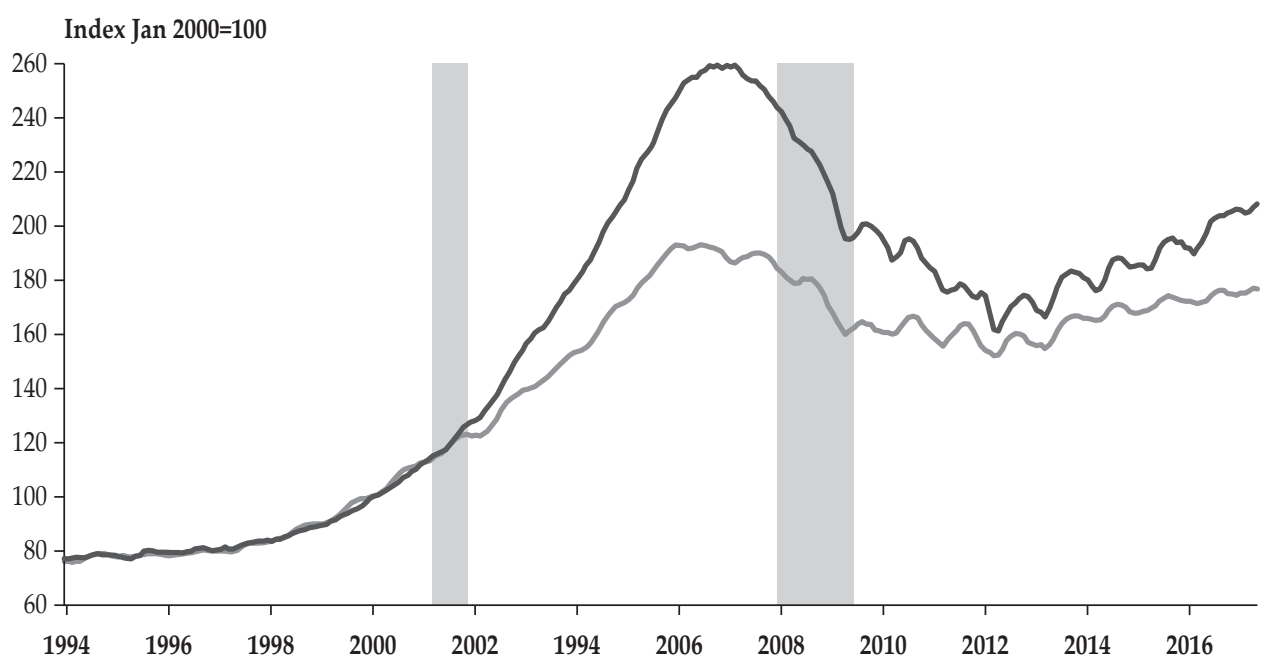

Home Price Index (High Tier) for New York, New York@

— Home Price Index (Low Tier) for New York, New York@

Source: S\&P Dow Jones Indices LLC

Fred.stlouisfed.org

Figure 9. Case-Shiller Home Price Index (High vs Low Tier) for Tampa, Florida

The figure shows the trend in the Case-Shiller home price index (high vs low tier) for Tampa, Florida (1994 to 2016).

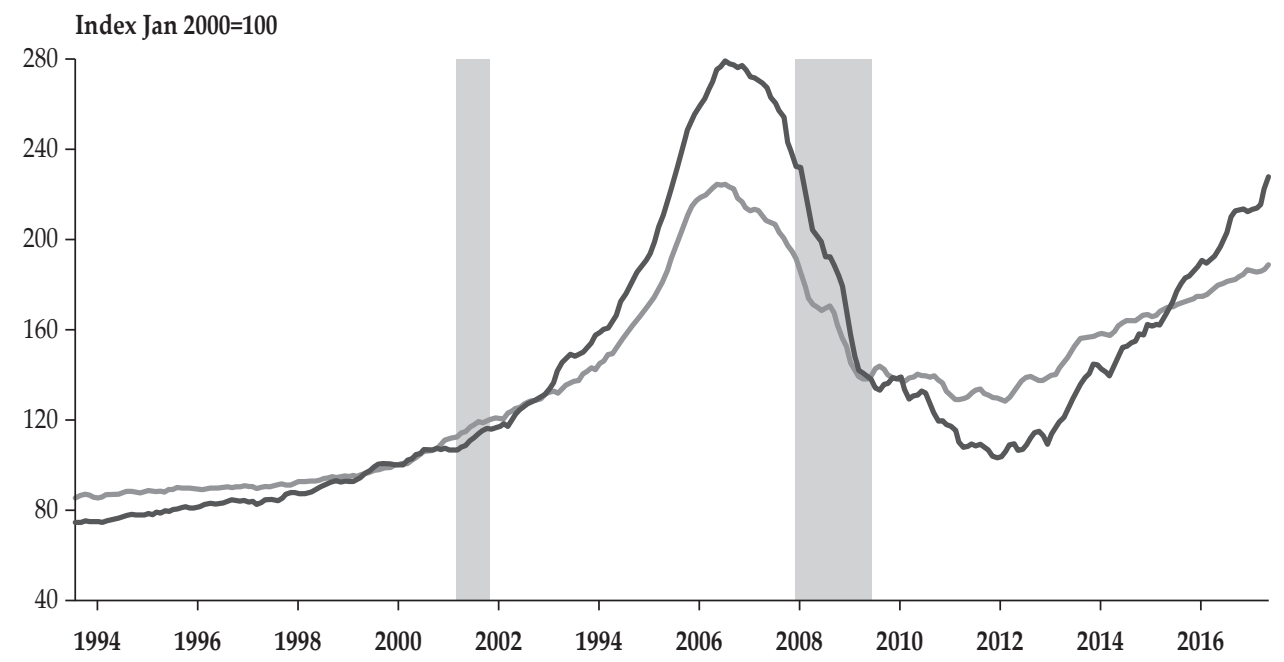

- Home Price Index (High Tier) for Tampa, Florida@

- Home Price Index (Low Tier) for Tampa, Florida®

Source: S\&P Dow Jones Indices LLC

Fred.stlouisfed.org 
Figure 10. Case-Shiller National, 10-City and 20-City Home Price Indices for the USA

The figure shows the trend in the Case-Shiller National, 10-City and 20-City Home Price Indices for the USA (1994 to 2016).

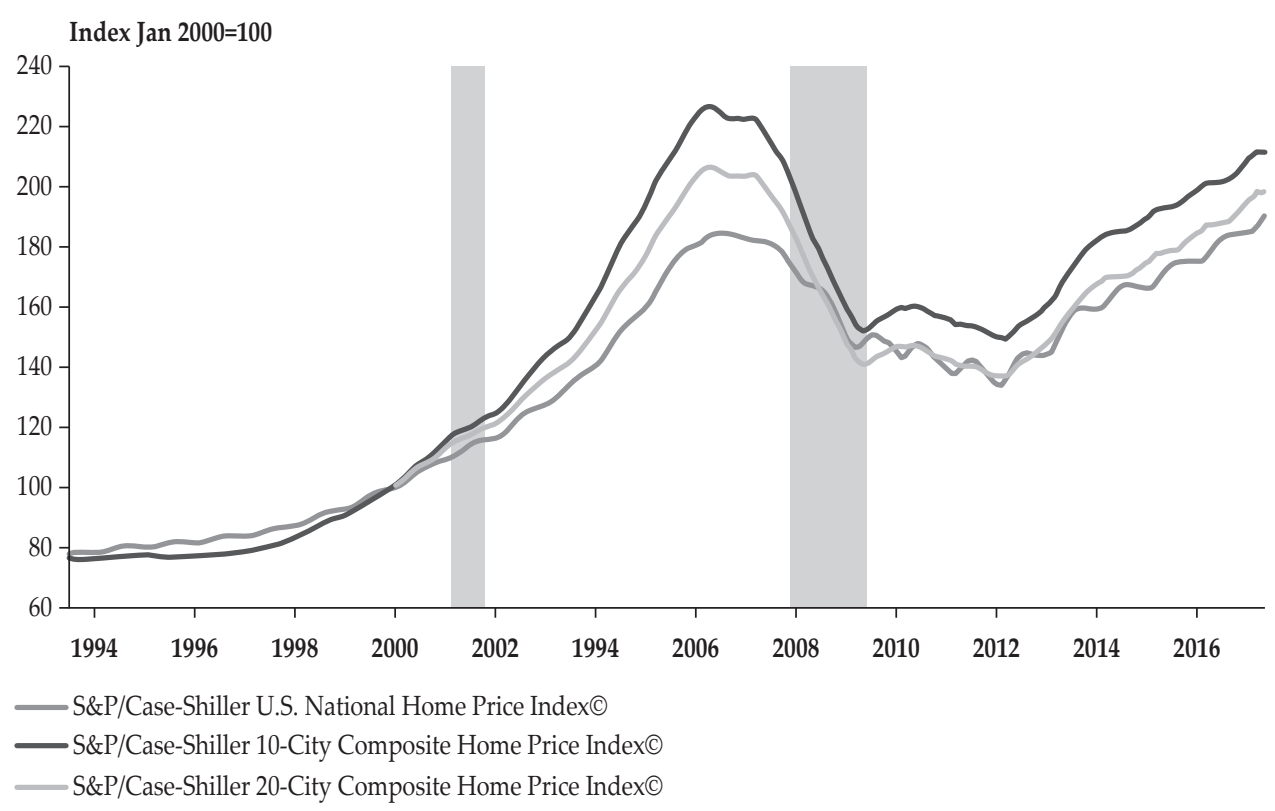

Source: S\&P Dow Jones Indices LLC

Fred.stlouisfed.org

Lemma 6 Suppose [A3] is violated $A<\underline{A}$, then the equilibrium in the rich market is similar to that of the poor market.

i. If $r_{2} \geq r$, then there exists an equilibrium $p_{t}^{R^{*}}=\bar{B}_{t}+D^{*}$ where $D^{*}=A<F^{R}$. IC $C_{R}$ does not bind and (8) binds, i.e the rich obtain a positive surplus from purchasing the asset.

ii. If $r_{2}<r$, then the rich borrow in equilibrium $B_{t}^{*}=B_{t+1}^{*}=\frac{A}{r-1}$, and equilibrium price is $p_{t}^{R^{*}}=p_{t+1}^{R}{ }^{*}=p^{*}=\frac{A r}{r-1}$.

Proof. The proof is similar to Lemma 2. For part (ii) the only difference from the poor is any price smaller than the endowment can be satisfied as equilibrium, and no agent borrows. The intuition is similar to Lemma 2, when the credit growth is smaller than the cost of borrowing, rich agents have an upper limit for the borrowing which is determined by the binding no default condition. Thus, the asset is traded below fundamental value since $p^{*}=\frac{A r}{r-1}<\frac{\underline{A} r}{r-1}=F^{R}$ since $\underline{A}=\frac{u}{r}$. 